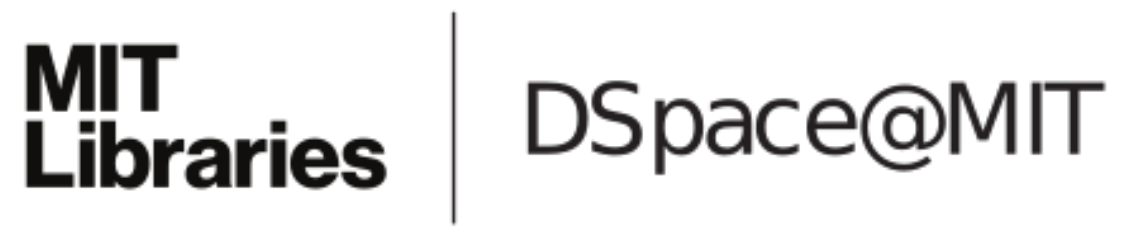

\author{
MIT Open Access Articles
}

Stimulation of the nucleus accumbens as behavioral reward in awake behaving monkeys

The MIT Faculty has made this article openly available. Please share how this access benefits you. Your story matters.

Citation: Bichot, Narcisse P., Matthew T. Heard, and Robert Desimone. "Stimulation of the Nucleus Accumbens as Behavioral Reward in Awake Behaving Monkeys." Journal of Neuroscience Methods 199, no. 2 (August 2011): 265-272.

As Published: http://dx.doi.org/10.1016/j.jneumeth.2011.05.025

Publisher: Elsevier

Persistent URL: http://hdl.handle.net/1721.1/102248

Version: Author's final manuscript: final author's manuscript post peer review, without publisher's formatting or copy editing

Terms of use: Creative Commons Attribution-Noncommercial-NoDerivatives 


\title{
Stimulation of the nucleus accumbens as behavioral reward in awake behaving monkeys
}

\author{
Narcisse P. Bichot ${ }^{\star}$, Matthew T. Heard ${ }^{\star}$, and Robert Desimone \\ Department of Brain and Cognitive Sciences, McGovern Institute for Brain Research, \\ Massachusetts Institute of Technology, Cambridge, MA
}

\begin{abstract}
It has been known that monkeys will repeatedly press a bar for electrical stimulation in several different brain structures. We explored the possibility of using electrical stimulation in one such structure, the nucleus accumbens, as a substitute for liquid reward in animals performing a complex task, namely visual search. The animals had full access to water in the cage at all times on days when stimulation was used to motivate them. Electrical stimulation was delivered bilaterally at mirror locations in and around the accumbens, and the animals' motivation to work for electrical stimulation was quantified by the number of trials they performed correctly per unit of time. Acute mapping revealed that stimulation over a large area successfully supported behavioral performance during the task. Performance improved with increasing currents until it reached an asymptotic, theoretically maximal level. Moreover, stimulation with chronicallyimplanted electrodes showed that an animal's motivation to work for electrical stimulation was at least equivalent to, and often better than, when it worked for liquid reward while on water control. These results suggest that electrical stimulation in the accumbens is a viable method of reward in complex tasks. Because this method of reward does not necessitate control over water or food intake, it may offer an alternative to the traditional liquid or food rewards in monkeys, depending on the goals and requirements of the particular research project.
\end{abstract}

\section{Keywords}

monkey; behavior; reward; motivation; electrical stimulation; nucleus accumbens

\section{INTRODUCTION}

Seminal studies in the 1950s-1960s demonstrated intracranial electrical brain stimulation reward in rodents, showing that the animals would press bars and navigate mazes to obtain direct current targeting the septal area, medial forebrain bundle, and parts of the hypothalamus (Olds and Milner, 1954; Olds, 1958; McIntire and Wright, 1965; Pliskoff et al., 1965). In contrast, nearly all behavioral training of non-human primates for neuroscience research has involved the control of food or fluid intake to motivate the animals to perform tasks for small amounts of food or water on each trial of a task as positive reinforcement (for

(C) 2011 Elsevier B.V. All rights reserved.

Corresponding author: Dr. Narcisse P. Bichot McGovern Institute for Brain Research Massachusetts Institute of Technology 77 Massachusetts Ave., 46-6121 Cambridge, MA 02139 Voice: (617) 324-3924 Fax: (617) 452-4119 bichot@ mit.edu .

* These two authors contributed equally to the work

Publisher's Disclaimer: This is a PDF file of an unedited manuscript that has been accepted for publication. As a service to our customers we are providing this early version of the manuscript. The manuscript will undergo copyediting, typesetting, and review of the resulting proof before it is published in its final citable form. Please note that during the production process errors may be discovered which could affect the content, and all legal disclaimers that apply to the journal pertain. 
a review, see Prescott, et al., 2010). Several decades ago, it was shown that electrical stimulation of several structures of the macaque brain, including the orbitofrontal cortex, lateral hypothalamus, amygdala, medio-dorsal nucleus of the thalamus, and the nucleus accumbens supports self-stimulation behavior (Briese and Olds, 1964; Routtenberg et al., 1971; Mora et al., 1979; Rolls et al., 1980). However, in all these studies, monkeys simply contacted a bar to initiate the stimulation at will, and no task with a cognitive load was performed to receive stimulation. Furthermore, it is not clear from these studies whether stimulation through chronically-implanted electrodes could lose its motivational effect as a result of habituation, damage to brain tissue as a result of repeated stimulation, or electrode failure due to its properties changing over time. In this study, we tested whether a monkey can be motivated to perform a cognitive task using brain stimulation as an alternative to fluid or food reward, and whether such a method would maintain its effectiveness and stability over periods spanning weeks or months. If so, electrical stimulation could potentially be used as an alternative to food or fluid reward in some neuroscience studies.

One such region that supports self-stimulation, the nucleus accumbens, lies within the ventral striatum at the interface of the midbrain and limbic system. Here, the accumbens is anatomically well-positioned to process information carried along the dopaminergic mesolimbic pathway. GABAergic, medium spiny neurons are the predominant cell type found within the accumbens, with most axons terminating in the pallidal nuclei (Haber et al., 1990). Accumbens inputs are mostly characterized by dopaminergic afferents from the ventral tegmental area and glutamatergic input from limbic structures (Lynd-Balta and Haber, 1994). The amygdala, for example, whose nuclei are essential in forming stimulusreward associations, influences activity in the ventral striatum through accumbens terminating axons (Cador et al., 1989).

Two important aspects of electrical self-stimulation of the accumbens are that, unlike some regions including the orbitofrontal cortex and the lateral hypothalamus, it is not affected by satiety (Mora et al., 1979; Rolls et al., 1980), and compared to many regions, it requires lower current thresholds (Mora et al., 1979). Moreover, its medial location and size make it a relatively compact, bilateral target for chronic electrode implantation. Based on these considerations and previous research, we explored the viability of using electrical stimulation of the accumbens in non-restricted primates as an alternative to traditional methods of liquid and food reward. This was achieved by: 1) testing the effect of current amplitude and the extent of the effective neural region from which stimulation supports behavior by extensive acute mapping in a monkey trained to perform a simple popout visual search task (e.g., Bichot and Schall, 1999), and 2) testing the long-term efficacy of this reward method and its efficacy relative to fluid reward (in a traditional, water-control paradigm), with chronically-implanted electrodes in another monkey trained to perform a more demanding, free-viewing visual search task (e.g., Bichot et al., 2005).

\section{MATERIALS AND METHODS}

\section{Subjects and surgical procedures}

Two rhesus monkeys weighing 10-12 kg were used. The animals were cared for in accordance with the National Institutes of Health Guide for the Care and Use of Laboratory Animals and the guidelines of the MIT Animal Care and Use Committee. All surgical procedures were carried out under anesthesia, and animals received antibiotics and analgesics after surgery. Under aseptic conditions, monkeys were implanted with a headpost and one or more chambers that allowed access to brain regions for electrical stimulation. Monkey BP was implanted with a single, large chamber (19 mm inner diameter, Crist Instruments Co., MD) over the accumbens of both hemispheres. A grid with holes $1 \mathrm{~mm}$ apart (Crist Instruments Co.) was used inside the chamber to guide electrode penetrations 
and localize them relative to MR images (MPRAGE, 500 micron isotropic). The large area covered by the chamber allowed acute mapping of the region from which stimulation supported behavioral performance. Monkey BD was implanted with two small chambers (5 $\mathrm{mm}$ diameter), one over the accumbens of each hemisphere for chronic electrode implantation to test long-term efficacy of the stimulation.

\section{Electrical stimulation}

Electrical stimulation was applied using a DS8000 stimulator in conjunction with DLS100 stimulus isolators in current-source mode (World Precision Instruments Inc., FL). Stimulation was delivered bilaterally at mirror locations in the form of charge-balanced biphasic pulses ( $0.2 \mathrm{~ms}$ negative followed by $0.2 \mathrm{~ms}$ positive) at $5 \mathrm{~ms}$ intervals $(200 \mathrm{~Hz}$ frequency); the total duration of the stimulation train was $200 \mathrm{~ms}$. Acute mapping was done with epoxylite-coated tungsten electrodes (FHC Inc., ME) that were positioned using a NAN drive (NAN Instruments Ltd., Israel). Chronically implanted electrodes were platinumiridium, insulated with polymide tubing over a Parylene coating (MicroProbes, MD). All electrodes had a diameter of $250 \mathrm{um}$ and had large exposed tips of $0.5 \mathrm{~mm}$. When the effect of different stimulation parameters was investigated, changes to stimulation parameters were either implemented across experimental sessions or after a 10-min break within a session. Stimulation delivery as reward was paired with an auditory tone that signaled correct performance as it did when water was the reward method.

\section{Behavioral tasks}

The experiments were under the control of a PC computer using MonkeyLogic software (University of Chicago, IL), which presented the stimuli, monitored eye movements, and triggered the delivery of the electrical or fluid reward. Monkeys were seated in an enclosed chair and their eye position was monitored using an EyeLink II infrared, video-based system (SR Research Ltd., Ontario, Canada). Stimuli were presented on an LCD video monitor (120 $\mathrm{Hz}, 1680 \times 1050$ resolution) viewed binocularly at a distance of $57 \mathrm{~cm}$ in a dark isolation box (Crist Instrument Co., MD). Monkeys were initially trained using water or juice reward while they were on fluid restriction and were then tested using electrical stimulation. However, monkey BD was trained on some additional variations of the task, including different stimulus conditions, using electrical stimulation.

Monkey BP was trained to perform a popout visual search task (Fig. 1A) for either a color singleton (red square among green squares) or a shape singleton (a cross among circles). The task alternated between the color popout search and the shape popout search every 10 correctly performed trials. Each trial began when the monkey fixated a white, central fixation spot. After $800 \mathrm{~ms}$ of fixation of the central spot, the search array was presented. The target occupied one of eight possible isoeccentric and equally spaced locations, with distractors occupying the remaining seven locations. The target location was chosen randomly across trials.

The monkey was rewarded for making a single saccade to the popout target location within $4 \mathrm{~s}$ of search array presentation, and maintaining fixation at the target location for $250 \mathrm{~ms}$. If the animal broke fixation or made a saccade to a distractor, the trial was aborted and no reward was given. A fixed $1 \mathrm{~s}$ inter-trial interval separated the end of one trial from the beginning of the next trial.

Monkey BD was trained to perform a more demanding free-viewing visual search task (Fig. 1B). The stimuli used in this task were a fixed set of eight natural object images that were matched for the number of pixels different from background, and subtended an area of approximately $1.5 \times 1.5 \mathrm{dva}$. After fixating a small, white central fixation point for $800 \mathrm{~ms}$, 
the monkey was presented with a central cue that informed it of the stimulus selected as the search target for that trial. The remaining seven stimuli became distractors for that trial. The cue stimulus stayed on for $1000 \mathrm{~ms}$, after which time it was extinguished and replaced by the fixation spot for another $500 \mathrm{~ms}$. The monkey was required to hold fixation at the center of the screen during this period, after which time the search array was presented and the monkey was required to fixate the target stimulus for $800 \mathrm{~ms}$ continuously to receive a reward. The animal had $10 \mathrm{~s}$ from search array onset to find the target, and no constraints were placed on its search behavior in order to allow it to conduct the search naturally. The inter-trial interval was $1 \mathrm{~s}$. The target location was selected pseudo-randomly such that, within an experimental block, there were ten repetitions of each stimulus presented as the target at each of twelve possible stimulus locations. Once the location for the target stimulus was selected, the remaining seven distractors occupied locations selected randomly from the remaining eleven. The target identity changed pseudo-randomly after the monkey correctly performed ten search trials with a given stimulus, and all eight stimuli became the target on an equal number of total correct trials within an experimental block. The search trials were interspersed with three consecutive detection trials each time the target stimulus changed and before the series of search trials commenced. The detection trials were identical to the search trials except that the target stimulus was presented alone (i.e., without distractors). If the animal completed an experimental block (1248 trials), a new block was started with the same constraints.

\section{RESULTS}

\section{Acute mapping during popout search}

We first determined the effect of current amplitude on behavioral performance during popout search. As shown in Fig. 2, both the number of trials the animal performed correctly per unit time (ANOVA, $\mathrm{F}(2,24)=27.1, \mathrm{p}<0.00001$ ), and its reaction time to initiate a saccade to the target $(\mathrm{F}(2,24)=6.2, \mathrm{p}<0.01)$ improved with increasing current amplitude applied at nine neural sites. The plots also show that performance starts to asymptote towards a maximal level, which was $\sim 21$ trials/min for this monkey in this task regardless of location or current amplitude. This is consistent with a minimum duration of two seconds to complete a trial (see Methods) without including the time to fixate the central spot once it appears in order to initiate the trial, and the saccadic reaction time of the response to the target. Occasional aborted trials due to broken fixations as a result of eye blinks or distraction further reduce the number of trials that could theoretically be completed successfully per unit of time. Thus, the monkey clearly responded to the electrical stimulation of the accumbens, and it did so as a function of the magnitude of the stimulation.

We then explored the anatomical extent of the neural tissue in and around the accumbens from which stimulation was effective in supporting behavior during popout search. To avoid a saturation (i.e., ceiling) effect on behavior that would mask differences among neural locations, we used a current of $300 \mu \mathrm{A}$ based on our finding above on the relationship between current amplitude and performance. As shown in Fig. 3, near-peak performance (18-21 trials/min) was obtained by stimulating 27 sites out of the 87 we tested, and good performance ( 15 trials/min or better) was obtained from half the sites. Such performance was attained by stimulating many locations within an area extending $3 \mathrm{~mm}$ mediolaterally, 7 $\mathrm{mm}$ dorsoventrally, and $8 \mathrm{~mm}$ rostrocaudally. The spatial distribution of the same stimulation sites in the sagittal plane is shown in Fig. S1.

\section{Stimulation with chronically-implanted electrodes during free-viewing search}

Two electrodes were implanted chronically and bilaterally in the region of the accumbens of the second animal. The location of these electrodes is shown in Fig. 4. To test the relative 
value of stimulation-based reward, we compared the second animal's performance on the free-viewing search task when it was not water-restricted and worked for stimulation of the accumbens to its performance when it was under water control (i.e. received most of its water in the testing session) and worked for water reward. We emulated a work-week scenario in which the animal was restricted on a given day, and testing on five consecutive days began 24 hours after the beginning of the water control. The results are shown in Fig. 5. Not surprisingly, the animal's motivation to work for water reward was very low the first day after the beginning of restriction, but improved significantly the next day. However, its motivation only improved modestly over the next two days, having apparently reached a stable level (the performance on the fifth day is intermediate between those on the third and fourth days during the same amount of time). In contrast, stimulation with a current of 1.5 $\mathrm{mA}$ yielded much stronger performance than any of the days when the monkey worked for water. By the 140-min mark, the monkey had worked for stimulation on average about twice the number of trials than on the first day on water reward, and 30\% more trials than on the best day on water reward (i.e., fourth day). The contrast between stimulation-reward and water-reward became even more apparent on the last day when the monkey worked for water and a longer data session was collected. In $3.5 \mathrm{hrs}$, the monkey had worked for stimulation 650 (or 50\%) more trials than for water.

Another important aspect of the animal's behavior for stimulation reward was that its performance rate was very stable even up to $3.5 \mathrm{hrs}$, while its performance rate for water reward started to decline early in the session and was much more variable. This can be seen by the fact that all the performance curves for water reward and the curve for $1.5 \mathrm{~mA}$ stimulation reward overlap up to approximately the 40-min mark. This is presumably the time period of highest motivation for the animal when receiving water reward, and the performance rate was at its peak of $\sim 10.5$ correct trials/min. However, after that time, while the performance rate for water starts to decline as the animal becomes increasingly satiated, the performance rate for stimulation is more or less unaffected. In fact, although performance decreased for the lower stimulation current of $1.0 \mathrm{~mA}$, as expected from our earlier observation during acute mapping (see Fig. 2), it was very steady, nearly reaching (compared to days 4 and 5), or surpassing (compared to days 1-3) performance for water reward. The higher stability of performance for stimulation reward is reflected in higher correlation coefficients in a linear regression for performance curves during stimulation (1.0 $\left.\mathrm{mA}: \mathrm{r}^{2}=.996 ; 1.5 \mathrm{~mA}: \mathrm{r}^{2}=.996\right)$ compared to those for water reward $(.892, .964, .961$, . $971, .973$, for days $1-5$, respectively).

We also compared the animal's performance when it worked for accumbens stimulation to when it worked for a fruit juice that we have found to be palatable to animals in our laboratory. As can be seen from the plots of Fig. S2, the animal usually performed better for juice than water. However, the advantage of the juice reward over water peaked on the second day, and then slowly declined with a performance below that for water on the fifth day. It is likely that the novelty effect of the juice contributed to the elevated performance on the first two days. Also, note that even in the best session (day 2), the animal's performance started declining after $\sim 1-1.5 \mathrm{hrs}$, and by the 3.5-hr mark the animal had performed $22 \%$ more correct trials for stimulation reward.

Since the animal's performance did not show signs of decline in the three sessions of 3.5hours of stimulation-reward, we ran an extended session to determine how long it would perform at a high rate. As can been seen from the results of this session (Fig. 6), the animal's performance was at a high and steady rate for six hours, but declined over the seventh hour. Fatigue and/or a loss of attention may have played a significant role in this decline. 
We also investigated the stability of behavioral performance for long-term, chronic stimulation reward across sessions. Performance rates for ten sessions in chronological order are shown in Fig. 7, showing that behavior did not decline with increasing number of sessions with rates ranging from 9.5 to 10.7 correct trials/min, essentially peak performance for the animal in this task. In contrast, for sessions of the same duration, performance rates for water reward ranged from 5.0 to 7.6 over the five consecutive days described above. Following these stimulation sessions of fixed duration, the animal performed an additional $\sim 10,000$ correct trials over more than 16 hours during neural recording sessions with an average rate of 9.9 correct trials/min using the same stimulation parameters; we found no evidence of decrease in the effectiveness of the stimulation. These data span a chronic electrode implantation duration of $\sim 7$ months.

Finally, we tested whether the observed reinforcing effects of the electrical stimulation depended on the stimulation being delivered bilaterally. We ran two sessions with alternating bilateral and unilateral stimulation, with a current of $1.5 \mathrm{~mA}$ and a reduced train duration of $100 \mathrm{~ms}$ to avoid ceiling effects on performance that may otherwise mask the effects of limiting stimulation to one side of the brain only. This also gave us the opportunity of testing the effect of reduced stimulation duration on performance. As shown in Fig. 8, unilateral stimulation with identical parameters reduced behavioral performance. While performance at the beginning and end of the sessions averaged 10.4 trials/min in both instances, stimulating the left-side only and right-side only in the middle portion of the sessions decreased performance rates similarly to 7.2 and 7.5 trials $/ \mathrm{min}$, respectively. While it is clear that unilateral stimulation is not as effective as bilateral stimulation (t-test, $\mathrm{p}<$ 0.01 ), it is possible that the magnitude of the effect was, to a certain extent, still masked due to the fact that stimulating with a reduced duration of $100 \mathrm{~ms}$ yielded very similar performance rates to those we observed with the duration of $200 \mathrm{~ms}$ (see Fig. 7; z-test, p = 0.11 ). Thus, while reducing stimulation duration by half did not have a significant impact on performance, applying the stimulation to only one side of the brain did affect its efficacy.

We also examined whether unilateral stimulation affected performance in a hemifielddependent manner. We found no differential effect of left vs. right hemisphere unilateral stimulation on performance (i.e., number of saccades or time to find target) as a function of target position in the left vs. right visual hemifield (Wilcoxon rank sum tests, $p>0.05$ ). The lack of laterality effects is consistent with the fact that unilateral stimulation resulted in a decrease of the animal's motivation to perform as evidenced by a large increase in trials during which it either did not fixate the central fixation spot to initiate the trial or broke fixation before the search array was presented $(37.3 \%$ and $35.2 \%$ of all trials for left and right unilateral stimulation conditions, respectively, compared to $14.9 \%$ for the bilateral stimulation condition). Also, when the animal did not break fixation and the array was presented, it completed correctly all but one trial in each of the unilateral stimulation conditions. The results show that unilateral stimulation affected the animal's willingness to initiate trials but not its ability to find the target once the array was presented.

\section{DISCUSSION}

We have shown that monkeys can be motivated to perform cognitive tasks (visual searches in our study) by electrical stimulation of the accumbens, and that the level of this motivation is current amplitude-dependent. Also, at least with the large electrode tips we used, the success of this stimulation does not seem to depend on precise localization within the accumbens. Furthermore, and perhaps most importantly, we found that for an appropriate amplitude of stimulation, an animal's performance is better compared to its performance working for water reward when it is under water control. 
Mechanisms mediating the motivational effect of the accumbens stimulation in our study are not clear. In fact, the mechanisms of deep brain stimulation (DBS) remain elusive, although it is known that its effects depend on the material and geometric configuration of the electrodes, stimulation parameters (such as amplitude and temporal characteristics), and the connectivity and other physiological properties of the DBS target (McIntyre et al., 2004; Kringelbach et al., 2007). Classical theory of our stimulation target, the accumbens, has emphasized its role in directly mediating the hedonistic characteristics of positive reinforcers (for a review, see Baldo and Kelley, 2007). Indeed, neurophysiological recording in behaving monkeys has revealed that accumbens neurons respond to primary food and liquid rewards (Apicella et al., 1991) as well as reinforcement-related stimuli (Williams et al., 1993). More recently, however, research and theory have described the accumbens' role in processing various aspects of reward-based learning, effort-related decision making, incentive salience, and goal-directed behavior (Schultz, 2000; Baldo and Kelley, 2007; Berridge, 2007; Salamone et al., 2009). For example, studies of reinforcement through ratio schedules suggest that accumbens dopamine regulates decision-making based upon effort expenditure (Salamone et al., 2007). It is possible that a combination of such reward and more complex motivation- and effort-related mechanisms may underlie the effects we observed in our study, consistent with a conservative view that dopamine acts in the accumbens and other structures "to reward immediate behavior and to establish conditioned motivational cues that will guide and motivate future behavior" (Wise, 2004). Wise (2004) has also speculated that "dopamine release in the ventral striatum, triggered by rewardassociated conditioned stimuli, acts primarily to energize the next response," which may be occurring in our experiment as a result of stimulating dopaminergic afferent axons to the accumbens (Nowak and Bullier, 1998a,b; McIntyre et al., 2004). Stimulation of the accumbens may also decrease the perceived effort of the task or maintain accumbens activity in response to rewards (e.g., liquid or food) that normally diminishes with overtraining (Schultz, 1993). However, it is important to note that in our study, stimulation of the accumbens was not paired with any other form of reward, but instead served as reward in and of itself.

This method of accumbens stimulation may not be suitable for neurophysiological explorations of reward mechanisms or of the brain structures involved in motivation or reward because the electrical stimulation almost certainly has "unnatural" rewarding properties. Food or fluid reward mimic conditions in the wild, where monkeys must work, face risks, and solve problems to obtain food and fluid each day (Desimone et al., 1992). Another potential drawback of electrical stimulation is that it requires chronic electrode implants which may interfere with other implants and also carry risks of infarcts or infections from the chamber, and these risks may be unacceptable in some studies. Another consideration is that mechanisms of perception, attention, or memory might potentially be expressed differently during stimulation reward, and thus control conditions using more conventional food or fluid reward may be required. Electrical stimulation also produces a strong electrical artifact during neural recordings at the time of the reward. On the other hand, in addition to potentially obtaining better performance from the animals, using stimulation may circumvent possible health issues and concerns due to fluid or food control (Prescott et al., 2010). We do not know how our animals experienced the reward, but longterm DBS of the accumbens has recently been shown to have antidepressant and anxiolytic effects in patients suffering from otherwise medically refractory neurological and psychiatric disorders (Schlaepfer et al., 2008; Malone et al., 2009; Bewernick et al., 2010; Blomstedt et al., 2011). The choice of whether to use electrical or natural motivators for behavior will always require a careful balancing of concerns and requirements for any given study. 


\section{Supplementary Material}

Refer to Web version on PubMed Central for supplementary material.

\section{Acknowledgments}

We thank Dr. Edmund Rolls for his very helpful advice and encouragement, and Jonathan Winkle and Grant Pielli for technical assistance. This work was supported by NIH grant EY017921 to RD.

\section{REFERENCES}

Apicella P, Ljungberg T, Scarnati E, Schultz W. Responses to reward in monkey dorsal and ventral striatum. Exp Brain Res. 1991; 85:491-500. [PubMed: 1915708]

Baldo B, Kelley A. Discrete neurochemical coding of distinguishable motivational processes: insights from nucleus accumbens control of feeding. Psychopharmacology (Berl). 2007; 191:439-59. [PubMed: 17318502]

Berridge K. The debate over dopamine's role in reward: the case for incentive salience. Psychopharmacology (Berl). 2007; 191:391-431. [PubMed: 17072591]

Bewernick BH, Hurlemann R, Matusch A, Kayser S, Grubert C, Hadrysiewicz B, Axmacher N, Lemke M, Cooper-Mahkorn D, Cohen MX, Brockmann H, Lenartz D, Sturm V, Schlaepfer TE. Nucleus accumbens deep brain stimulation decreases ratings of depression and anxiety in treatment-resistant depression. Biol Psychiatry. 2010; 67:110-6. [PubMed: 19914605]

Bichot NP, Schall JD. Saccade target selection in macaque during feature and conjunction visual search. Vis Neurosci. 1999; 16:81-89. [PubMed: 10022480]

Bichot NP, Rossi AF, Desimone R. Parallel and serial neural mechanisms for visual search in macaque area V4. Science. 2005; 308:529-534. [PubMed: 15845848]

Blomstedt P, Sjoberg RL, Hansson M, Bodlund O, Hariz MI. Deep brain stimulation in the treatment of depression. Acta Psychiatr Scand. 2011; 123:4-11. [PubMed: 20961293]

Briese E, Olds J. Reinforcing brain stimulation and memory in monkeys. Exp Neurol. 1964; 10:493508. [PubMed: 14239736]

Cador M, Robbins TW, Everitt BJ. Involvement of the amygdala in stimulus-reward associations: interaction with the ventral striatum. Neuroscience. 1989; 30:77-86. [PubMed: 2664556]

Desimone R, Olson C, Erickson R. The controlled water access paradigm. ILAR J. 1992; 34:27-9.

Haber S, Lynd E, Klein C, Groenewegen H. Topographic organization of the ventral striatal efferent projections in the rhesus monkey: an anterograde tracing study. J Comp Neurol. 1990; 293:28298. [PubMed: 19189717]

Kringelbach M, Jenkinson N, Owen S, Aziz T. Translational principles of deep brain stimulation. Nat Rev Neurosci. 2007; 8:623-35. [PubMed: 17637800]

Lynd-Balta E, Haber S. The organization of midbrain projections to the ventral striatum in the primate. Neuroscience. 1994; 59:609-23. [PubMed: 7516505]

Malone DA Jr. Dougherty DD, Rezai AR, Carpenter LL, Friehs GM, Eskandar EN, Rauch SL, Rasmussen SA, Machado AG, Kubu CS, Tyrka AR, Price LH, Stypulkowski PH, Giftakis JE, Rise MT, Malloy PF, Salloway SP, Greenberg BD. Deep brain stimulation of the ventral capsule/ ventral striatum for treatment-resistant depression. Biol Psychiatry. 2009; 65:267-75. [PubMed: 18842257]

McIntire R, Wright J. Differences in extinction in electrical brain-stimulation under traditional procedures of reward presentation. J Comp Physiol Psychol. 1965; 59:131-4. [PubMed: 14282392]

McIntyre C, Savasta M, Kerkerian-Le Goff L, Vitek J. Uncovering the mechanism (s) of action of deep brain stimulation: activation, inhibition, or both. Clin Neurophysiol. 2004; 115:1239-48. [PubMed: 15134690]

Mora F, Avrith D, Phillips A, Rolls E. Effects of satiety on self-stimulation of the orbitofrontal cortex in the rhesus monkey. Neurosci Lett. 1979; 13:141-5. [PubMed: 119182] 
Nowak L, Bullier J. Axons, but not cell bodies, are activated by electrical stimulation in cortical gray matter I. Evidence from chronaxie measurements. Exp Brain Res. 1998; 118:477-88. [PubMed: 9504843]

Nowak L, Bullier J. Axons, but not cell bodies, are activated by electrical stimulation in cortical gray matter II. Evidence from selective inactivation of cell bodies and axon initial segments. Exp Brain Res. 1998; 118:489-500. [PubMed: 9504844]

Olds J. Self-stimulation of the brain: Its use to study local effects of hunger, sex, and drugs. Science. 1958; 127:315. [PubMed: 13506579]

Olds J, Milner P. Positive reinforcement produced by electrical stimulation of septal area and other regions of rat brain. J Comp Physiol Psychol. 1954; 47:419-27. [PubMed: 13233369]

Pliskoff SS, Wright JE, Hawkins TD. Brain stimulation as a reinforcer: intermittent schedules. J Exp Anal Behav. 1965; 8:75-88. [PubMed: 14271317]

Prescott M, Brown V, Flecknell P, Gaffan D, Garrod K, Lemon R, Parker A, Ryder K, Schultz W, Scott L. Refinement of the use of food and fluid control as motivational tools for macaques used in behavioural neuroscience research: Report of a Working Group of the NC3Rs. J Neurosci Methods. 2010; 193:167-88. [PubMed: 20868708]

Rolls E, Burton M, Mora F. Neurophysiological analysis of brain-stimulation reward in the monkey. Brain Res. 1980; 194:339-57. [PubMed: 6770964]

Routtenberg A, Gardner E, Huang Y. Self-stimulation pathways in the monkey, Macaca mulatta. Exp Neurology. 1971; 33:213-24.

Salamone J, Correa M, Farrar A, Mingote S. Effort-related functions of nucleus accumbens dopamine and associated forebrain circuits. Psychopharmacology. 2007; 191:461-82. [PubMed: 17225164]

Salamone J, Correa M, Farrar A, Nunes E, Pardo M. Dopamine, behavioral economics, and effort. Front Behav Neurosci. 2009; 3:13. [PubMed: 19826615]

Schlaepfer T, Cohen M, Frick C, Kosel M, Brodesser D, Axmacher N, Joe A, Kreft M, Lenartz D, Sturm V. Deep brain stimulation to reward circuitry alleviates anhedonia in refractory major depression. Neuropsychopharmacology. 2008; 33:368-77. [PubMed: 17429407]

Schultz W. Multiple reward signals in the brain. Nat Rev Neurosci. 2000; 1:199-207. [PubMed: 11257908]

Schultz W, Apicella P, Ljungberg T. Responses of monkey dopamine neurons to reward and conditioned stimuli during successive steps of learning a delayed response task. J Neurosci. 1993; 13:900-13. [PubMed: 8441015]

Williams G, Rolls E, Leonard C, Stern C. Neuronal responses in the ventral striatum of the behaving macaque. Behav Brain Res. 1993; 55:243-52. [PubMed: 8395182]

Wise R. Dopamine, learning and motivation. Nat Rev Neurosci. 2004; 5:483-94. [PubMed: 15152198] 
Research Highlights

$>$ We explored a novel method of reward for neuroscience studies using monkeys

$>$ Monkeys performed cognitive tasks for electrical stimulation of their accumbens

$>$ Performance for accumbens stimulation was superior to that for water reward

$>$ This method may offer an alternative to liquid/food rewards in restricted animals

$>$ Its applicability will depend on the particular research project's requirements 


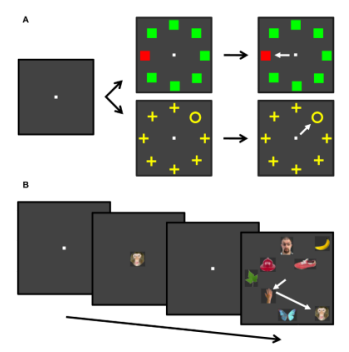

Figure 1.

Behavioral tasks. A. Popout search for a color singleton (red square among green squares) or for a shape singleton (yellow circle among yellow crosses). The two search types alternated in blocks. The white arrow represents the saccade from the central fixation spot to the singleton target. B. Free-viewing visual search. In this example, the cue/target was the monkey face, and the animal made two saccades (represented by the sequence of white arrows) before finding the target stimulus. Stimuli are not drawn to scale. 

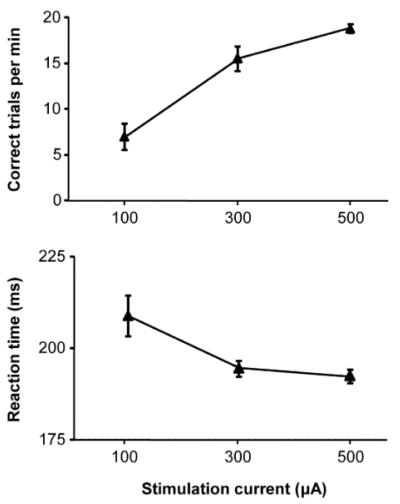

Figure 2.

Effect of stimulation current amplitude on performance rate (A) and saccadic reaction time (B) during popout search. Error bars represent the standard error of the mean. 


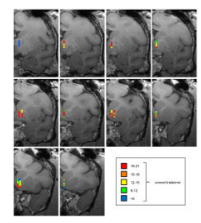

Figure 3.

Map of behavioral performance during popout search supported by electrical stimulation at different anatomical locations. Current amplitude was $300 \mu \mathrm{A}$. Each small, colored square represents the behavioral measure of performance (average number of correct trials per minute) at that anatomical location. The stimulation sites were theoretically reconstructed based on an MRI scan and a grid used to localize penetrations within the chamber as well as offering support for making straight electrode penetrations. The different colors of the squares represent different ranges of behavioral performance (see legend). MRI scan slices are ordered in a posterior-to-anterior sequence from the top left one (most posterior) to the bottom right one (most anterior). 

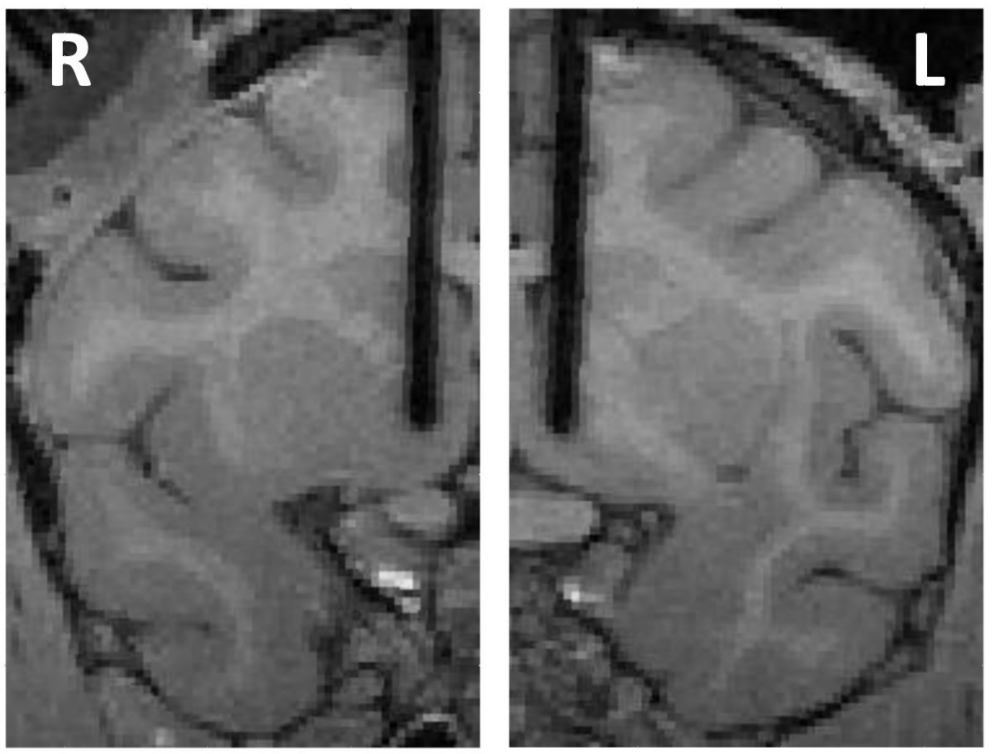

Figure 4.

Location of chronically-implanted electrodes in the left $(\mathrm{L})$ and right $(\mathrm{R})$ hemispheres. 


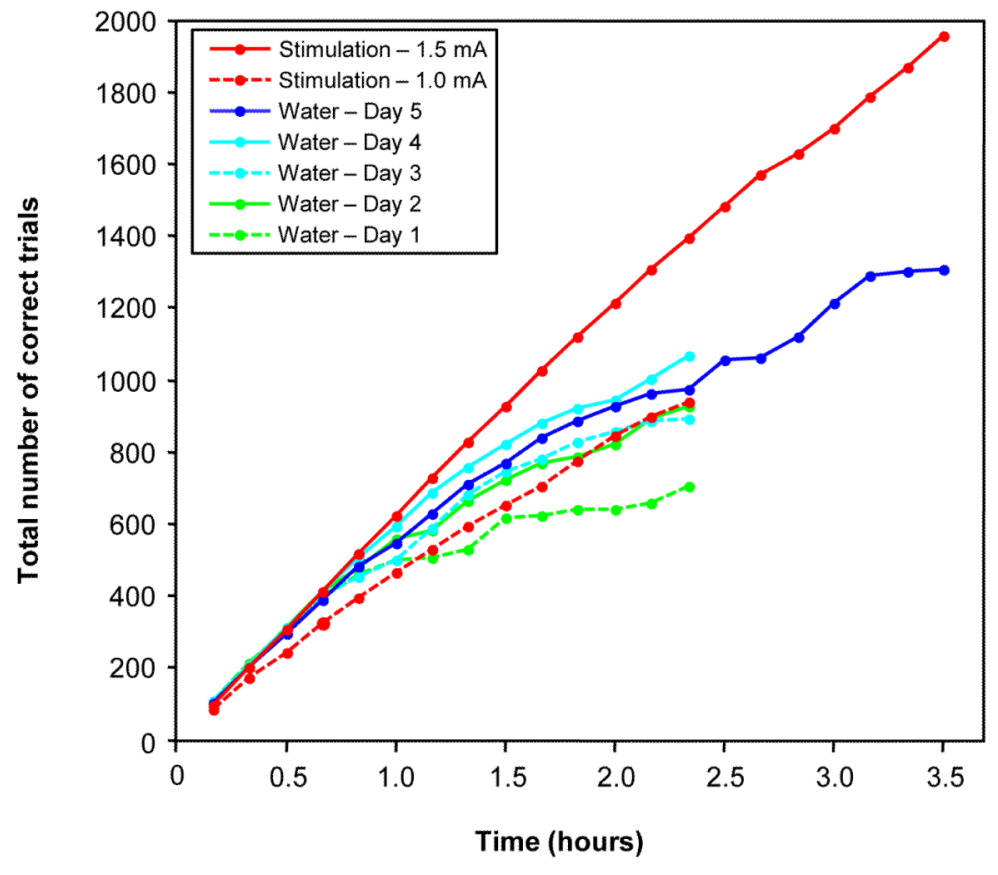

Figure 5.

Motivational effect of electrical stimulation with chronically implanted electrodes on performance during free-viewing search, and its comparison to the motivational effect of fluid reward during water restriction. Each curve plots the cumulative number of trials performed correctly as a function of time. The curves for stimulation-reward represent the average of three sessions each, while the curves for water-reward represent a session each over five consecutive days starting 24 hours after water restriction was implemented. 


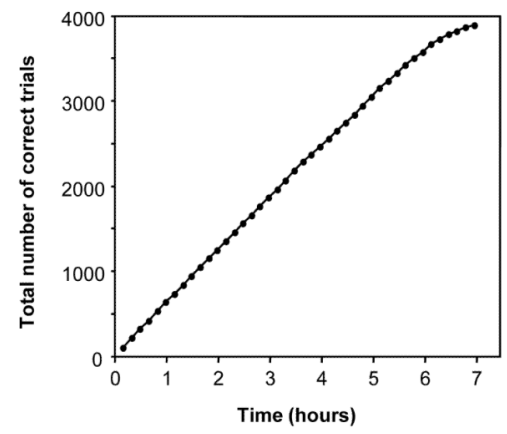

Figure 6.

Behavioral performance for stimulation reward during an extended session. Current amplitude was $1.5 \mathrm{~mA}$. 


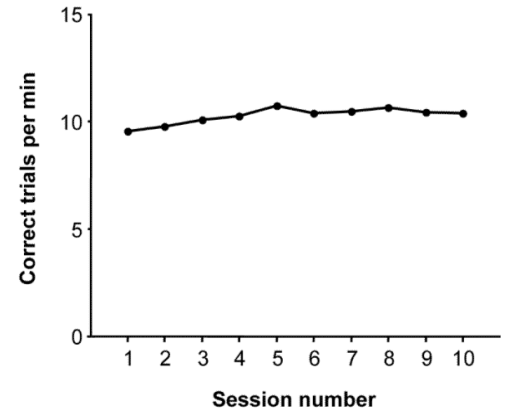

Figure 7.

Behavioral performance for stimulation reward across sessions. The sessions are ordered chronologically. All data were for a session duration of 140 minutes. 


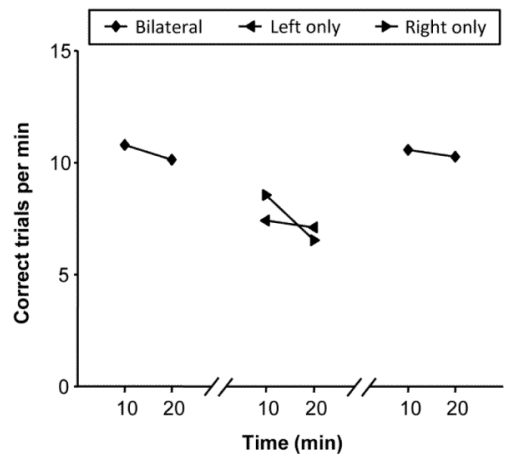

Figure 8.

Effect of bilateral vs. unilateral stimulation on behavioral performance. Current amplitude was $1.5 \mathrm{~mA}$, but stimulation train duration was reduced to $100 \mathrm{~ms}$. The curves are the average of two sessions. To avoid effects of testing order, the first session was run in the bilateral, left side only, right side only, and bilateral again sequence. For the second session, the order of the two unilateral sides was reversed (i.e., right side only first, then left side only). Each combination (i.e., bilateral, left only, right only) was tested for 20 minutes with a 10-minute break between each test. Each data point reflects performance during a nonoverlapping 10-minute duration. 